\title{
A Participação do Cliente em Processos de Serviço e as Implicações dos Possíveis Papéis do Cliente na Criação de Valor
}

\author{
Noel Torres Júnior, Dr. \\ Departamento de Ciências Administrativas - Faculdade de Ciências Econômicas - Universidade \\ Federal de Minas Gerais \\ noel@face.ufmg.br
}

Dario Ikuo Miyake, PhD. Departamento de Engenharia de Produção, Escola Politécnica da USP, São Paulo/SP dariomiy@usp.br

Vários trabalhos têm discutido a importância da maior participação dos clientes nos processos de serviços. A consideração do envolvimento do cliente implica na necessidade de examinar os papéis que ele pode desempenhar. Neste contexto, este trabalho explora os diferentes papéis que o cliente poderia desempenhar e enumera treze papéis fundamentais identificados numa revisão da literatura: cliente como agente de inovação, comprador, concorrente do provedor de serviço, coprodutor, competidor de outros clientes, parceiro de outros clientes, instrutor, insumo para o processo, quase-gerente, usuário, auditor, produto do processo e promotor do serviço. Um quadro conceitual é proposto relacionando os papéis que o cliente pode desempenhar com funções que na perspectiva da empresa agregam valor. Com o propósito de investigar a ocorrência destes papéis e o modo como os mesmos são explorados, foi realizado um estudo de múltiplos casos em quatro empresas de serviços que têm como objeto principal de seu processo os próprios clientes. Nos processos considerados, foi constatado que o cliente é diretamente envolvido na entrega dos serviços contemplando-se oportunidades para o exercício da maior parte dos papéis discutidos. Verificou-se, também, que diferentes estratégias para efetivar e/ou aperfeiçoar a participação do cliente podem ser buscadas pelas empresas e assim promover maior envolvimento dos clientes.

Palavras-chave: Papéis dos clientes, Operações de Serviços, Agregação de Valor.

Several studies have discussed the importance of greater customer involvement in service processes. The consideration of customer involvement in services entails the need to discuss the roles that the customer can play. In this context, this paper explores the different roles that the customer could undertake in services and points out a set of thirteen roles identified in a literature review: customer as an agent of innovation, purchaser, competitor for the service provider, co-producer, rival of other customers, partner of other customers, instructor, resource for the process, substitute for leadership, user, auditor, result of the process, and advocate of the service. A 
conceptual framework is proposed to relate the roles customers can play to functions that are value-adding from the provider's viewpoint. In order to investigate the occurrence of these roles and the mode how they are exploited, a multiple cases research was carried out considering a sample of four companies in which the main object processed are the customer themselves. In the observed processes, it was observed that the client is directly involved in the delivery of service what brings opportunities to employ most of the considered roles. Also, it was verified that different strategies for the implementation and/or improvement of customer participation can be pursued by the companies, and thus nurture greater customer involvement.

Keywords: Customer Roles, Operations Services, Value Adding.

\section{INTRODUÇÃO}

Em um trabalho pioneiro na área, Chase (1978) propôs a classificação dos diferentes serviços considerando a variável grau de contato do cliente com o sistema. Essa dimensão baseia-se no tempo de contato do primeiro com o segundo. Mais especificamente, refere-se ao percentual dado pelo período em que o cliente permanece em contato com o sistema em relação ao prazo total necessário para que o serviço seja realizado. Os sistemas de serviço podem ser classificados como serviços puros (alto contato), mistos (médio contato) ou quase manufatura (baixo contato). Considerando esta variável, Chase (1978) defende que as organizações de serviço diminuam o tempo de contato com os clientes para aumentarem sua eficiência produtiva. Nesta direção, Levitt (1972) defende a chamada "abordagem da linha de produção" segundo a qual a participação do cliente no processo deve ser restringida para que a eficiência produtiva do sistema de prestação de serviço não seja prejudicada. Os defensores desta abordagem argumentam que o sistema de prestação de serviços deveria ser isolado ao máximo dos clientes, a fim de reduzir a incerteza que eles podem introduzir no processo produtivo, haja vista a influência que teriam no cumprimento dos prazos e a dificuldade de controlar suas atitudes.

Por outro lado, vários trabalhos posteriores discutiram a importância de considerar uma maior participação do cliente nos processos de produção de serviços (LOVELOCK e YOUNG, 1979; BOWEN, 1986; MILLS e MORRIS, 1986). Alguns autores têm advogado a necessidade de uma maior participação do cliente, não apenas agindo como um "co-produtor", mas atuando em novos papéis (cliente como um inovador, cliente como promotor do serviço, etc.) para que a empresa consiga, com a maior participação do mesmo, oferecer-lhe efetivamente mais valor (WIKSTRÖM, 1996; PRAHALAD e RAMASWAMY, 2000; VON HIPPEL, 2001; OUSCHAN, SWEENEY e JOHNSON, 2006). Etgar (2008) e Hilton (2007) ressaltam que a maior participação do cliente fornece mais alternativas para a empresa customizar seus produtos.

Lusch, Vargo e Wessels (2008) postulam a necessidade de estudar o serviço sob uma nova perspectiva que eles denominam de "service-dominant logic". Segundo estes autores, com esta nova perspectiva, o serviço pode ser melhor compreendido pois a lógica atualmente dominante foi concebida tratando os serviços

principalmente em termos de unidades de produto o que evoca a busca da 
eficiência. A perspectiva alternativa enfatiza a eficácia do serviço sob o ponto de vista do cliente e pode ser decomposta em três princípios: (1) conceituação do serviço como um processo, ao invés de uma unidade de produto; (2) enfoque em recursos dinâmicos, tais como conhecimentos e competências, em vez de recursos estáticos, como os recursos naturais, e (3) entendimento de que o valor de um serviço emerge de um processo colaborativo entre fornecedores e clientes.

Vários trabalhos apontam a crescente importância da participação do cliente para a criação de valor nas empresas. É cada vez mais evidente às empresas que não basta estarem direcionadas ao atendimento das necessidades de seus clientes: elas necessitam de uma mudança para além deste posicionamento aprendendo a explorar a interação com os seus clientes no processo de criação de valor. Portanto, o incentivo à participação do cliente tende a se tornar uma abordagem de grande relevância para se atingir a eficácia competitiva. Nesta nova lógica, os clientes devem ser entendidos como agentes ativos de co-criação de valor e as empresas devem ser compreendidas como facilitadoras do processo de co-criação de valor (AUH et al, 2007; BENDAPUDI e LEONE, 2003; CHAN, YIM e LAM, 2010; PAYNE, STORBACKA e FROW, 2008).

Diante deste novo quadro, o presente trabalho explora os diferentes papéis que o cliente pode desempenhar em sistemas de serviços, com base na premissa de que em determinadas circunstâncias, a atuação do cliente em certos papéis promove a efetiva realização do processo de serviço e pode contribuir no esforço de agregação de valor da empresa e, portanto, isso deveria ser previsto, planejado e estimulado. Assim sendo, o trabalho apresenta diferentes estratégias consideradas na literatura de marketing e de operações de serviços para o provedor efetivar e/ou aperfeiçoar a participação do cliente. Também propõe um quadro conceitual que relaciona os papéis que o cliente pode desempenhar com funções que segundo a perspectiva de Möller e Törrönen (2003) contribuem para criar valor em um provedor de serviços. Finalmente, este trabalho apresenta e discute as diversas estratégias identificadas em estudos de casos conduzidos em organizações que processam os próprios clientes (e não o bem ou a informação dos clientes).

\section{MÉTODOS E TÉCNICAS DE PESQUISA}

Por tratar de um problema de pesquisa sobre o qual o conhecimento ainda está difuso, tendo como propósito central, proporcionar maior familiaridade com o mesmo e torná-lo mais explícito, o caráter do presente trabalho pode ser caracterizado conforme Gil (1991) como exploratório. Quanto ao entendimento que se busca sobre o fenômeno objeto de estudo, ele requer uma investigação no contexto vivenciado pelos gestores de processos de serviço que necessitam ampliar a visão e compreensão das formas de atuação dos clientes em serviços para melhor direcionar o seu planejamento e operação. Assim, o trabalho emprega a abordagem de estudo de caso que, segundo Yin (2001), é indicado para pesquisas que analisam um fenômeno contemporâneo em um contexto real.

O estudo de caso é particularmente apropriado quando a pergunta de pesquisa concentra-se em "como" e "por quê" os fenômenos observados acontecem, quando não há necessidade de controle sobre o comportamento dos eventos, e quando o enfoque estiver em eventos contemporâneos (YIN, 2001). 
O estudo teve como propósito investigar os papéis assumidos pelos clientes em determinados serviços procurando melhor compreendê-los à luz da perspectiva "service-dominant". Mais especificamente, utilizou-se o método do estudo de múltiplos casos. A opção por esta abordagem deve-se à pretensão de obter resultados e conclusões que não sejam específicos a um particular caso e que tenham a possibilidade de serem considerados numa gama mais ampla de organizações. A possibilidade de estender os achados do estudo àquelas organizações que compartilham características comuns favorece sua validade interna no contexto do tipo de organização a que pertencem os casos contemplados (McCUTCHEON e MEREDITH, 1993). O desenvolvimento do presente trabalho apoiou-se no estudo de uma amostra constituída de quatro casos em empresas que se caracterizam por ter como objeto principal do processo os próprios clientes envolvendo-os diretamente na entrega dos serviços. Este tipo de serviço permite uma maior participação do cliente no processo de prestação de serviços possibilitando a verificação de uma variedade maior de papéis que o cliente pode desempenhar em serviços (TORRES JÚNIOR, 2007). A amostra dos casos selecionados é apresentada e discutida na seção 4.1.

O protocolo adotado para a condução da coleta de dados empíricos em cada unidade de análise incluiu a realização de uma visita com um tour pelas suas instalações físicas e uma entrevista com um gestor responsável pelas operações. Utilizou-se um roteiro semi-estruturado que direcionou a coleta de dados sobre os principais processos estabelecidos pelas empresas para a entrega dos serviços, e sobre as atividades realizadas pelos clientes no desempenho dos possíveis papéis que eles podem assumir nestes serviços. Este roteiro está descrito no Anexo A. As entrevistas foram complementadas por outras fontes, como pesquisa bibliográfica, pesquisa documental e observação direta.

\section{REFERENCIAL TEÓRICO}

\subsection{Papéis do Cliente}

O modo como os clientes podem se inserir em processos de serviços tem sido objeto de estudo de diversos trabalhos. Contudo, como sugere o levantamento apresentado na Figura 1, a diversidade do conjunto de possíveis papéis do cliente que já foram identificados pela literatura de marketing e de operações de serviços enumerados nas linhas - é tão ampla que nenhuma das formas de classificação propostas parece ser capaz de satisfatoriamente acomodar todos eles. A partir de uma análise conceitual dos mesmos, o presente trabalho organiza uma relação de treze papéis fundamentais que contempla com suficiente abrangência as diversas perspectivas identificadas. Este conjunto de papéis fundamentais é apresentado nas colunas, à direita da Figura 1. As marcas ao longo de cada coluna apontam as relações existentes entre um papel fundamental e múltiplos papéis retratados na literatura considerada, independentemente de ser uma correspondência em grau maior ou menor. É importante ressalvar que estes papéis fundamentais contemplam apenas os modos em que o cliente atua como "participante" interferindo no serviço ou para o serviço. Assim sendo, embora até haja o entendimento de que a "não participação" do cliente como ator Inerte ou "Idle" também pode ser um possível 
papel (Chervonnaya, 2003), tal alternativa não é considerada no presente trabalho por fugir do escopo de contemplação dos modos de atuação participante do cliente. 


\begin{tabular}{|c|c|c|c|c|c|c|c|c|c|c|c|c|c|c|c|}
\hline \multirow[b]{2}{*}{$\begin{array}{l}\widehat{\Phi} \\
\frac{\Phi}{2} \\
\frac{0}{3} \\
\frac{\mathbb{\alpha}}{2}\end{array}$} & \multirow[b]{2}{*}{$\begin{array}{l}\text { Papéis tratados pela } \\
\text { literatura }\end{array}$} & \multirow[b]{2}{*}{ Explicações e/ou comentários acerca dos papéis } & \multicolumn{13}{|c|}{ Papéis fundamentais } \\
\hline & & & 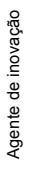 & 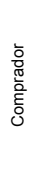 & 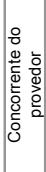 & 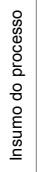 & 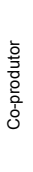 & 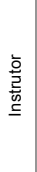 & 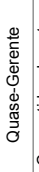 & 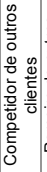 & 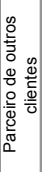 & : & 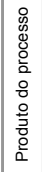 & 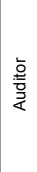 & $\frac{\bar{c}}{\grave{\circ}}$ \\
\hline \multirow{5}{*}{ 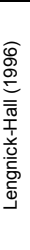 } & Recurso & $\begin{array}{l}\text { O cliente pode fornecer diferentes fatores de produção. Em alguns serviços, além de } \\
\text { tais fatores, o próprio cliente pode passar por uma transformação. }\end{array}$ & & & & V & & & & & & & & & \\
\hline & Co-produtor & $\begin{array}{l}\text { O cliente pode assumir a execução de várias atividades do processo de entrega do } \\
\text { serviço no lugar dos funcionários. }\end{array}$ & & & & & $\mathrm{v}$ & & & & & & & & \\
\hline & Usuário & O cliente recebe diretamente o serviço e se beneficia dele. & & & & & & & & & & v & & & \\
\hline & Comprador & O cliente que define o produto. & & v & & & & & & v & & & & & \\
\hline & Produto & O estado final do processo é o próprio cliente transformado. & & & & & & & & & & & v & & \\
\hline \multirow{3}{*}{ 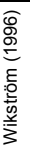 } & Co-produtor no projeto & $\begin{array}{l}\text { O cliente interage com o fornecedor de modo que o fornecedor concebe e produz um } \\
\text { produto que atende às suas necessidades específicas. }\end{array}$ & V & & & v & & & & & & & & & \\
\hline & Co-produtor na produção & O cliente finaliza o produto para obter um melhor resultado e reduzir o custo. & & & & & v & & & & & & & & \\
\hline & Co-produtor no consumo & $\begin{array}{l}\text { A empresa realiza atividades que apóiam e facilitam o consumo do produto pelo } \\
\text { cliente. }\end{array}$ & & & & & & & & & & v & & $\mathrm{v}$ & \\
\hline \multirow{3}{*}{ 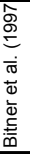 } & Recurso produtivo & $\begin{array}{l}\text { Contribui fornecendo insumos para a empresa e participa em atividades produtivas } \\
\text { como um "funcionário parcial". }\end{array}$ & & & & v & V & & & & v & & & & \\
\hline & $\begin{array}{l}\text { Contribuinte para a qualidade, } \\
\text { satisfação e valor do serviço }\end{array}$ & $\begin{array}{l}\text { Cliente é parte integral do serviço e realiza várias atividades para a obtenção dos } \\
\text { resultados desejados. }\end{array}$ & & & & $\mathrm{v}$ & v & $\mathrm{v}$ & & & v & v & v & v & v \\
\hline & Competidor da empresa & Capaz de executar todo o serviço sozinho sem o auxilio do provedor. & & & v & & & & & & & & & & \\
\hline \multirow{10}{*}{ 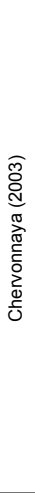 } & Inerte & O cliente não pode participar do serviço. & & & & & & & & & & & & & \\
\hline & "Idle" & O cliente pode mas não participa do serviço. & & & & & & & & & & & & & \\
\hline & Instrutor & Fonte de conhecimentos para a empresa. & & & & & & $\mathrm{v}$ & & & & & & & \\
\hline & Ingrediente & Serve como fonte de insumo (informação) para a empresa. & & & & v & & & & & & & & & \\
\hline & "Janus" & $\begin{array}{l}\text { Assume o papel de co-produção, sendo ao mesmo tempo produtor e consumidor do } \\
\text { serviço. }\end{array}$ & & & & & $\mathrm{V}$ & & & & & v & & & \\
\hline & Auditor & Julga a qualidade do processo e do output do serviço. & & & & & & & & & & & & v & \\
\hline & Competidor & Capaz de executar todo o serviço sozinho sem o auxilio do provedor. & & & $\mathrm{v}$ & & & & & & & & & & \\
\hline & "Marketer" & Recomendar o serviço para outros potenciais clientes. & & & & & & & & & & & & & v \\
\hline & "Decision-maker" & Define se ele próprio ou um terceiro utilizará o serviço. & & v & $\mathrm{v}$ & & & & & & & & & & \\
\hline & "Hunter" & Define qual empresa fará o serviço. & & $\mathrm{v}$ & & & & & & & & & & & \\
\hline \multirow{6}{*}{ 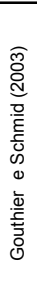 } & "Co-designer" & $\begin{array}{l}\text { Importante fonte para o planejamento e introdução de um novo serviço ou melhoria } \\
\text { de um já existente. }\end{array}$ & $\mathrm{V}$ & & & & & & & & & & & & \\
\hline & Co-produtor & Fornece insumos para o processo ou se envolve no processo de produção do serviço. & & & & v & $\mathrm{v}$ & & & & & & & & \\
\hline & "Co-interactor" & $\begin{array}{l}\text { Possibilita que o serviço seja realizado ao interagir com a empresa e outro(s) } \\
\text { cliente(s). }\end{array}$ & & & & & & & & & v & & & & \\
\hline & "Substitute for leadership" & $\begin{array}{l}\text { Assume funções que geralmente são desempenhadas pelos gerentes como, por } \\
\text { exemplo, motivar os funcionários. }\end{array}$ & & & & & & & v & & & & & & \\
\hline & Comprador & $\begin{array}{l}\text { O cliente que remunera a prestação do serviço. Muitas vezes o comprador e usuário } \\
\text { são idênticos. }\end{array}$ & & $\mathrm{v}$ & & & & & & v & & v & & & \\
\hline & "Co-marketer" & Promover o serviço por meio da propaganda "boca-a-boca". & & & & & & & & & & & & & v \\
\hline \multirow{7}{*}{ 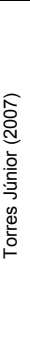 } & Recurso & $\begin{array}{l}\text { O cliente pode fornecer diferentes fatores de produção: informação, dinheiro, idéias, } \\
\text { material a ser processado, etc. O próprio cliente pode ser um input. }\end{array}$ & & & & $\mathrm{v}$ & & & & & & & & & \\
\hline & Co-produtor & $\begin{array}{l}\text { O cliente pode assumir a execução de várias atividades do processo de entrega do } \\
\text { serviço no lugar dos funcionários }\end{array}$ & & & & & v & & & & & & & & \\
\hline & Comprador & O cliente define a aquisição do serviço. & & v & & & & & & v & & & & & \\
\hline & Usuário & O cliente recebe diretamente o serviço e se beneficia dele. & & & & & & & & & & v & & & \\
\hline & Produto & $\begin{array}{l}\text { Resultado buscado é a mudança de comportamento ou atitudes por parte do cliente } \\
\text { ou a modificação de uma dada condição do cliente para outra. }\end{array}$ & & & & & & & & & & & v & & \\
\hline & Concorrente de outros clientes & $\begin{array}{l}\text { O cliente pode agir de modo indesejável disputando com terceiros os serviços ou } \\
\text { recursos oferecidos pelo prestador de serviço. }\end{array}$ & & & & & & & & v & & & & & \\
\hline & Parceiro de outros clientes & O cliente pode colaborar com outros clientes no processo de serviço & & & & & & & & & $v$ & & & & \\
\hline \multirow{3}{*}{ 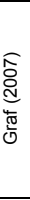 } & Fonte de competência & $\begin{array}{l}\text { Clientes auxiliam a empresa na procura por novos clientes. Solicitam novas soluções } \\
\text { desafiando o provedor a buscar novos conhecimentos. }\end{array}$ & V & $\mathrm{v}$ & & v & & v & v & & & v & & & v \\
\hline & Inovador & $\begin{array}{l}\text { O know-how e competências dos clientes são transformados em novos produtos e } \\
\text { serviços. Os clientes realizam parte do desenvolvimento por meio de instrumentos } \\
\text { disponibilizados pelas empresas. }\end{array}$ & V & $\mathrm{v}$ & & $\mathrm{v}$ & $\mathrm{v}$ & & & & & & & & \\
\hline & "Advocate" & $\begin{array}{l}\text { Os clientes tornam-se defensores do processo de criação de valor e atuam como } \\
\text { principais atores neste papel. Os clientes podem se tornar desenvolvedores, } \\
\text { fabricantes e consumidores de seus produtos e serviços. }\end{array}$ & V & v & & v & V & v & v & & & v & & v & v \\
\hline
\end{tabular}

Figura 1 - Principais papéis do cliente identificados na literatura e sua relação com as classes de papéis fundamentais consideradas no trabalho 
A literatura destaca as características relativas ao envolvimento do cliente que são essenciais para sucesso da empresa enfatizando o papel do cliente como um co-produtor, mas a participação do cliente não se restringe apenas a este papel. A participação do cliente deve ser vista de modo mais amplo, podendo ser entendida como a atuação requerida do próprio cliente por meio de seu engajamento em uma ou mais atividades específicas que constituem o serviço. Portanto, a participação do cliente é dependente do tipo de serviço e das suas necessidades. Ela é determinada pelo(s) papel(éis) que o cliente deseja ou aceita desempenhar dentro do processo de serviço. O espectro de envolvimento do cliente varia de uma participação mais passiva até um grau em que o serviço é quase que completamente conduzido pelo próprio cliente (GRAF, 2007). A revisão da literatura revelou vários papéis que o cliente pode desempenhar nos serviços os quais são descritos a seguir.

\subsubsection{Cliente como Agente de Inovação}

A empresa pode envolver o cliente no planejamento de um novo serviço a ser oferecido, solicitando suas idéias e sugestões para a definição das atividades que irão compor o processo de serviço (WIKSTRÖM, 1996). É importante aproveitar o know-how e a competência dos clientes no projeto de novos serviços. Os clientes do tipo lead-users podem desempenhar um papel importante neste modo de participação. As empresas podem ser ativas na busca de inovações desenvolvidas por usuários com este perfil identificando-os pelo tipo de suporte que solicitam e pela qualidade de seus questionamentos. As empresas também podem solicitar que os seus clientes definam o que esperam que o serviço faça para eles. Os resultados esperados do serviço desejado pelos clientes fornecem oportunidades para 0 desenvolvimento de novos serviços (ULWICK, 2002).

\subsubsection{Cliente como Comprador}

Neste papel, o cliente avalia o serviço a ser adquirido com base em atributos sujeitos à análise, experiência e credibilidade, e seleciona o serviço de um determinado provedor ou de outro. Os atributos de análise podem ser determinados antes da compra (são exemplos: peso, cheiro, volume, etc), mas são poucos os presentes nos serviços e os atributos de experiência podem ser avaliados durante e depois do processo de produção. Já os atributos de credibilidade não podem ser avaliados com confiança, mesmo imediatamente após o recebimento do serviço e requerem mais tempo e informação para serem estabelecidos (HOFFMAN e BATESON, 2003). Tornar o cliente um comprador permanente traz vários benefícios para a empresa. Neste sentido, Lovelock e Wright (2002) observam que são vários os ganhos advindos da retenção dos clientes. Quanto mais um cliente permanece com uma empresa, mais lucrativo torna-se servi-lo. Além disso, os custos iniciais para atrair clientes fiéis podem ser amortizados no decorrer de um período mais longo que pode se estender a muitos anos. Há quatro fatores que trabalham a favor do provedor de serviços na obtenção de lucros crescentes por meio da fidelização do cliente: i) lucro derivado do aumento das compras; ii) lucro por redução de custos 
operacionais; iii) lucro por indicação de outros clientes; e iv) lucro por preço superior. Os benefícios econômicos da lealdade de seus clientes frequentemente explicam por que uma empresa é mais lucrativa do que uma concorrente.

\subsubsection{Cliente como Concorrente do Provedor}

Um papel que também pode ser protagonizado pelos clientes é o de concorrente potencial. Em muitas situações, tanto indivíduos como empresas têm a escolha de comprar serviços oferecidos no mercado ou de eles próprios produzirem o serviço que necessita em sua totalidade ou de maneira parcial. Portanto, de certo modo, os clientes podem ser concorrentes das empresas provedoras de serviços (BITNER et al., 1997).

\subsubsection{Cliente como Insumo do Processo}

O cliente pode fornecer diferentes fatores de produção ao processo de serviço tais como dados, dinheiro, idéias e material a ser processado. As informações provenientes dos clientes são fundamentais para o planejamento do serviço. Dados incompletos ou errados podem levar a atrasos, retrabalhos ou mesmo a falhas na execução do serviço desejado. Portanto, a empresa deve buscar meios para assegurar que todos os dados necessários sejam coletados e estejam corretos. Em alguns serviços, além de tais fatores, o próprio cliente é o input que irá passar por uma transformação (LENGNICK-HALL, 1996).

\subsubsection{Cliente como Co-Produtor}

O cliente pode assumir a execução de várias atividades do processo de entrega do serviço no lugar dos funcionários do provedor. Neste papel, o cliente é mobilizado como um recurso produtivo, ou seja, como um "funcionário parcial" (BOWEN, 1986; MILLS e MORRIS, 1986). Vários incentivos podem ser identificados quando este participa como co-produtor:

- preços mais baixos, uma vez que a empresa pode obter redução de custo com a maior eficiência no uso de recursos;

- a auto-estima do cliente é elevada por causa do aumento do grau de controle que pode exercer;

- o cliente passa a poder aplicar sua própria discrição e ter mais oportunidades de fazer escolhas;

- os tempos de espera podem ser reduzidos;

- possibilita maior personalização do serviço (LENGNICK-HALL, 1996).

Para que a participação do cliente seja bem-sucedida, Bowen (1986) realça a importância de orientá-lo e treiná-lo adequadamente para a execução de suas tarefas, assegurando que ele seja capaz de executá-las. Isso implica também na 
empresa definir de forma simples, consistente e clara que tarefas deverão ser realizadas pelo cliente e de que modo.

\subsubsection{Cliente como Instrutor}

Em serviços intensivos em conhecimento, como atividades de consultoria empresarial, o cliente também "ensina" os funcionários do provedor de serviço. Este aprendizado, por parte do provedor, se faz necessário para que o serviço seja entregue de acordo com as necessidades do cliente. Este papel exige boas habilidades de comunicação para instruir ou orientar o provedor de serviço, como também assegurar que o conhecimento requerido seja efetivamente transferido para o provedor. O cliente tem de definir que partes de seu conhecimento tecnológico e/ou organizacional podem ser transferidas e que partes devem ser mantidas em segredo (CHERVONNAYA, 2003).

\subsubsection{Cliente como Quase-Gerente}

O termo quase-gerente sugere que o cliente pode assumir algumas das funções que normalmente são executadas pelos gerentes do serviço. Por exemplo, o cliente pode influenciar na motivação, nas atitudes e no comportamento do atendente de linha de frente. Também pode determinar as tarefas a serem executadas bem como induzir os funcionários ao desenvolvimento de novas competências (GOUTHIER e SCHMID, 2003).

\subsubsection{Cliente como Competidor de Outros Clientes}

Em muitos serviços, a entrega não é feita somente para um cliente. Os clientes, muitas vezes, interagem com outros durante este processo. Esta situação ocorre porque eles recebem o serviço simultaneamente com outros, ou porque devem esperar a sua vez, enquanto outros estão sendo atendidos. Nestes casos, como Bitner et al. (1997), Grove e Fisk (1997) e Zeithaml e Bitner (2003) observam, os outros clientes podem afetar positivamente ou negativamente a natureza dos resultados. O efeito negativo ocorre quando num ambiente coletivo, um cliente age de modo indesejável a outros clientes. Vários textos de marketing de serviços reportam a existência de clientes "abusivos", que normalmente prejudicam a experiência de serviço de outros clientes. Além disso, o cliente pode ainda, simplesmente, disputar com terceiros os mesmos recursos ou serviços oferecidos pelo provedor que está sujeito a uma restrição de capacidade, e quanto mais intensa for esta disputa, maior tende a ser a insatisfação que isso pode causar (TORRES JÚNIOR, 2007). 


\subsubsection{Cliente como Parceiro de Outros Clientes}

Diferentemente do que ocorre no papel anterior, a interação entre diferentes clientes num ambiente coletivo ou compartilhado, pode também ser positiva. Isso ocorre quando a interação se dá na forma de parceria ou colaboração. Nestes casos, é desejável que ocorra maior interação e aproximação entre os diferentes clientes e a empresa deve buscar meios para promover a socialização entre eles (ZEITHAML e BITNER, 2003).

\subsubsection{Cliente como Usuário}

Neste papel, o cliente recebe diretamente o serviço e se beneficia dele. Como usuário, define dois resultados importantes: i) percebe e mede a discrepância entre suas expectativas e a experiência de serviço recebida; e ii) determina o seu nível de satisfação (ZEITHAML e BITNER, 2003).

\subsubsection{Cliente como um Produto do Processo}

Trata-se de uma situação em que o produto - resultado buscado pelo processo de entrega do serviço - é a modificação de uma dada condição do cliente para outra ou a mudança de comportamento ou atitude por parte do cliente. $\mathrm{O}$ resultado esperado depende da disposição do próprio cliente em querer mudar. Assim, o cliente tanto no papel de comprador como no de usuário, pode afetar o resultado na medida em que ele deve se interessar pelo serviço e cumprir de modo adequado suas atividades (LENGNICK-HALL, 1996).

\subsubsection{Cliente como Auditor}

O cliente pode agir como "auditor" de um serviço quando tiver bom conhecimento do mesmo e for capaz de avaliar a qualidade do serviço recebido. Um bom auditor é uma pessoa treinada para observar (estar atenta aos detalhes), e dotada das capacidades de pensar analiticamente e de articular suas idéias com clareza e de modo convincente. Dependendo das características do serviço em questão, algumas destas habilidades se tornam mais importantes que outras. Por exemplo, para serviços relativamente simples como uma pequena viagem de ônibus a capacidade de observação pode ser suficiente; já serviços como a implementação de um certo sistema de informação numa empresa exigem do cliente um grande conhecimento de informática (CHERVONNAYA, 2003). 


\subsubsection{Cliente como Promotor do Serviço}

Quando os clientes são capazes de atuar como auditores, eles podem atuar também a favor ou contra o provedor na promoção do serviço avaliado passando uma imagem positiva ou negativa do serviço para outras pessoas (CHERVONNAYA, 2003). Habilidades de comunicação são críticas para atuar neste tipo de papel. Isto significa que o cliente deve ser capaz de:

- Selecionar os clientes adequados para divulgar sua opinião;

- Saber escolher a hora e o lugar adequados para realizar a divulgação do serviço; e

- Ser convincente ao divulgar o serviço (ter uma boa capacidade de argumentação).

\subsection{Papéis do Cliente Sob a Ótica do Processo}

Segundo a literatura de gerenciamento de operações de serviços, os serviços podem ser melhor entendidos se considerados como um processo de transformação. Considerando esta perspectiva, vários autores utilizam um modelo de transformação para descrever a criação dos serviços (HAKSEVER et al., 2000; SLACK et al., 2001; WEMMERLÖV, 1990; JOHNSTON e CLARK, 2008). Para um modelo deste tipo, genericamente, o serviço abrange três grandes fases, quais sejam:

- Pré-processamento: envolve basicamente a escolha do serviço, sua solicitação pelo cliente e o seu planejamento pelo provedor e/ou cliente;

- Processamento do serviço: envolve a entrega do serviço ao cliente. Três elementos se fazem presentes nesta fase, quais sejam: input, processo e output;

- Pós-processamento: nesta fase o provedor finaliza sua entrega e o cliente recebe finalmente o output do serviço.

O contexto em que os diferentes papéis apresentados são exercidos pode ser delimitado em função das três grandes fases que compõem um processo de serviço. A Figura 2 posiciona as possíveis ocorrências desses papéis nestas fases. 


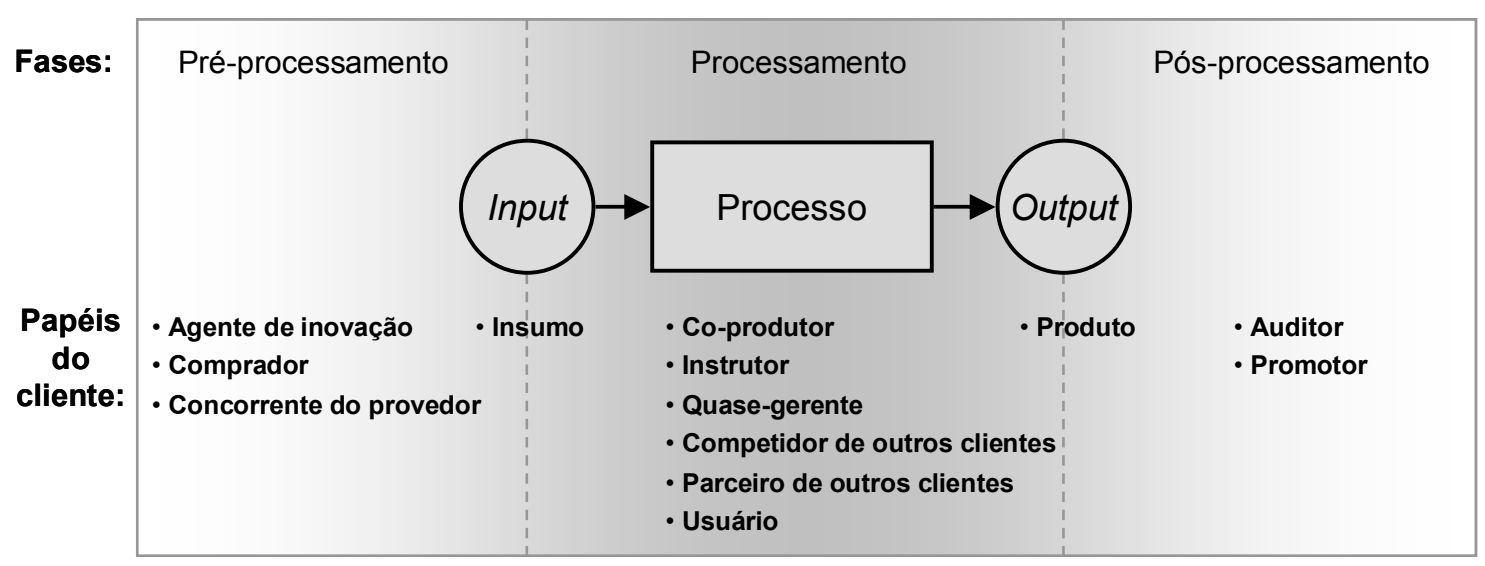

Figura 2-Ocorrência dos possíveis papéis do cliente conforme as fases do serviço

\subsection{Promovendo a Participação do Cliente}

Sob o ponto de vista da operação de serviços, as empresas devem compreender quais papéis os clientes podem desempenhar e devem promover as formas de participação que podem levar a uma melhoria da qualidade e produtividade dos serviços. Para assegurar uma relação positiva entre a participação dos clientes e os resultados desejados do serviço Claycomb, Lengnick-Hall e Inks (2001) ressaltam que as organizações precisam tornar claros as formas de participação esperadas e os benefícios que podem ser auferidos com elas. O Quadro 1 indica as principais táticas reportadas na literatura como meios de promoção de uma maior participação dos clientes. É importante ressaltar que os papéis não podem ser vistos como independentes entre si, pois podem estar interrelacionados. Por exemplo, o papel do cliente enquanto comprador depende da percepção da qualidade do serviço que é influenciada pela avaliação que o cliente realiza no papel de auditor.

Quadro 1 - Papéis do cliente e principais táticas que promovem maior participação dos clientes.

\begin{tabular}{|c|c|}
\hline $\begin{array}{c}\text { Papéis do } \\
\text { cliente }\end{array}$ & \multicolumn{1}{|c|}{ Táticas que promovem maior participação dos clientes } \\
\hline $\begin{array}{c}\text { Agente de } \\
\text { inovação }\end{array}$ & $\begin{array}{l}\text { Implementar programas que capturem as inovações desenvolvidas pelos clientes. } \\
\text { Estruturar o processo de desenvolvimento de serviços para que o cliente seja } \\
\text { envolvido no planejamento do serviço. } \\
\text { Fornecer "ferramentas" que possibilitem a execução de atividades inerentes ao } \\
\text { projeto pelo cliente. }\end{array}$ \\
\hline Comprador & $\begin{array}{l}\text { Implementar programas de fidelidade. } \\
\text { Instituir garantias de serviço. } \\
\text { Planos com descontos conforme o tempo ou frequência de uso. }\end{array}$ \\
\hline $\begin{array}{c}\text { Concorrente } \\
\text { do provedor }\end{array}$ & $\begin{array}{l}\text { Em relação a este papel, o gestor pode inibir a atuação do cliente no mesmo, } \\
\text { informando as vantagens do serviço oferecido em relação à alternativa dele } \\
\text { mesmo fazer o serviço. }\end{array}$ \\
\hline $\begin{array}{c}\text { Insumo do } \\
\text { processo }\end{array}$ & $\begin{array}{l}\text { Segmentar o mercado buscando clientes com características compatíveis (horário, } \\
\text { preferências, perfil sócio-econômico, etc.). } \\
\text { Realizar diagnóstico do cliente de modo a identificar o processo de serviço mais } \\
\text { adequado. }\end{array}$ \\
\hline
\end{tabular}




\begin{tabular}{|c|c|}
\hline & $\begin{array}{l}\text { Informar e educar o cliente quanto à importância e ao tipo das informações que são } \\
\text { necessárias para se iniciar o processo de entrega do serviço. }\end{array}$ \\
\hline Co-produtor & $\begin{array}{l}\text { Orientar e treinar adequadamente o cliente para a execução das suas tarefas, } \\
\text { assegurando que seja capaz de executá-las corretamente. } \\
\text { Fornecer antecipações realistas sobre o serviço como um meio de tornar os clientes } \\
\text { cientes de seus papéis de co-produção. } \\
\text { Premiar ou recompensar a participação do cliente. }\end{array}$ \\
\hline Instrutor & Recompensar a maior participação dos clientes neste papel. \\
\hline $\begin{array}{l}\text { Quase- } \\
\text { gerente }\end{array}$ & $\begin{array}{l}\text { (não foi identificada nenhuma indicação de tática para estimular este papel na } \\
\text { literatura consultada) }\end{array}$ \\
\hline $\begin{array}{l}\text { Competidor } \\
\text { de outros } \\
\text { clientes }\end{array}$ & $\begin{array}{l}\text { Em relação a este papel, o gestor pode adotar medidas como as seguintes para } \\
\text { inibir comportamentos que podem prejudicar outros clientes: i) definir regras de } \\
\text { conduta que devem ser respeitadas pelos clientes quando utilizam os serviços; ii) } \\
\text { implementar programas de educação e orientação (aulas formais, folhetos, placas } \\
\text { de orientação, etc.); iii) penalizar clientes por mau comportamento; iv) administrar } \\
\text { o composto de clientes de forma que segmentos conflitantes não se misturem. }\end{array}$ \\
\hline $\begin{array}{l}\text { Parceiro de } \\
\text { outros } \\
\text { clientes }\end{array}$ & $\begin{array}{l}\text { Quando for desejável que haja maior interação e aproximação entre os diferentes } \\
\text { clientes, a empresa pode realizar atividades como festas, excursões e passeios } \\
\text { para promover maior socialização entre os clientes e até recompensar clientes } \\
\text { que cultivem a parceria com outros clientes. }\end{array}$ \\
\hline Usuário & $\begin{array}{l}\text { Estabelecer uma comunicação eficiente com o cliente, disponibilizando informações } \\
\text { relevantes sobre o serviço, como programação, preços, instruções para o uso dos } \\
\text { serviços, lembretes, avisos, notificação de mudanças, etc. } \\
\text { Prover suporte ao cliente durante a realização das atividades, orientando, } \\
\text { esclarecendo dúvidas e estimulando sua participação. }\end{array}$ \\
\hline $\begin{array}{l}\text { Produto do } \\
\text { processo }\end{array}$ & $\begin{array}{l}\text { Incentivar a conclusão do serviço com sucesso. } \\
\text { Desestimular ou penalizar a desistência. }\end{array}$ \\
\hline Auditor & $\begin{array}{l}\text { Disponibilizar instrumentos adequados (formulários, sites, etc) para o cliente realizar } \\
\quad \text { a avaliação do serviço. } \\
\text { Treinar e capacitar os clientes como "auditores". } \\
\text { Premiar ou recompensar a participação do cliente como auditor. }\end{array}$ \\
\hline Promotor & Premiar ou recompensar a participação do cliente como promotor. \\
\hline
\end{tabular}

Fontes: Lovelock (1995); Lovelock e Wright (2002); Lengnick-Hall (1996); Zeithaml e Bitner (2003); Wikström (1996); Graf (2007); Torres Júnior (2007); Torres Júnior e Miyake (2008).

\subsection{A Participação do Cliente em Funções de Agregação de Valor}

$\mathrm{Na}$ literatura de gestão de operações, prevalece o entendimento de que as empresas só têm condições de existência se oferecer alguma proposta de valor a seus clientes. O valor é um conceito bastante explorado na literatura de gestão. Apesar disto e por isto, não se consegue uma concordância em torno de sua definição. Dada a essencialidade do valor para as empresas, é importante que seus gestores consigam compreender os mecanismos que possibilitam a sua criação. A maioria dos trabalhos que tratam desta questão se concentra na criação de valor para os clientes assumindo que as empresas apenas serão bem sucedidas no mercado se forem capazes de oferecer mais valor a seus clientes do que os concorrentes (RAVALD e GRÖNROOS, 1996; MCNAUGTON, OSBORNE e IMRIE, 2002).

Vários trabalhos apontam que os gestores de serviços podem criar valor para a empresa estabelecendo um maior e melhor relacionamento com seus clientes, haja visto que as empresas podem adquirir dos mesmos, além de receitas monetárias, novas idéias sobre produtos/processos, acesso ao mercado e a novas tecnologias (WALTER, RITTER e GEMUNDEN, 2001). Isso reforça a necessidade 
de aprofundar a discussão sobre o estabelecimento de um maior envolvimento dos clientes no processo de serviço e de um melhor relacionamento com os mesmos em busca de novas oportunidades de criação de valor.

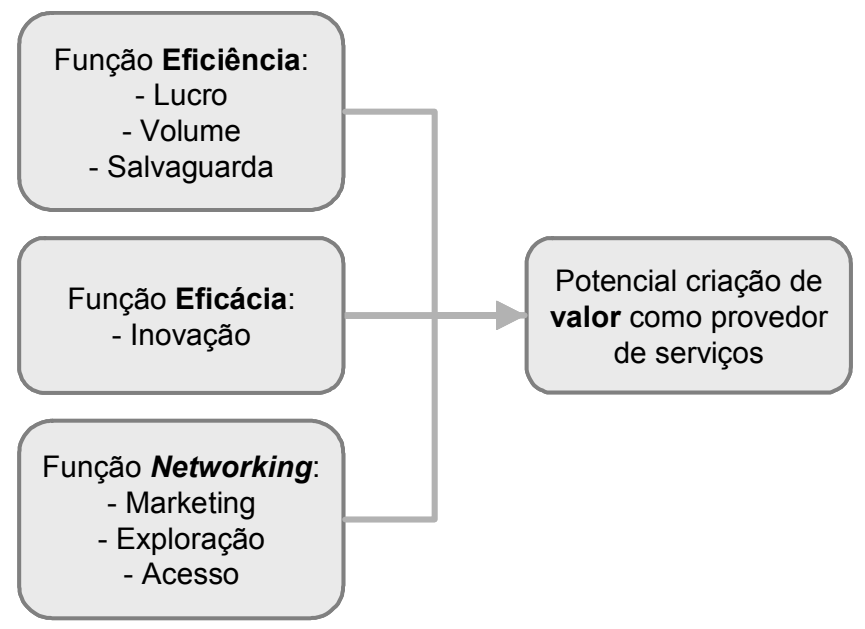

Figura 3 - As funções contribuintes para a agregação de valor em um provedor de serviços Fonte: Adaptada da Figura 1 de Möller e Törrönen (2003).

Sob o paradigma funcionalista, o termo função refere-se à contribuição de um elemento para um sistema maior do qual ele faz parte. No presente estudo, as funções do cliente no relacionamento com o seu provedor se referem às atividades realizadas e à disponibilização de recursos pelos clientes (ex. dinheiro, informação, material a ser processado) para a execução do serviço. Estas podem ser classificadas como diretas ou indiretas. As funções diretas incluem atividades e recursos que criam valor para o provedor sem estarem conectadas ou dependentes de outros relacionamentos, podendo ser divididas em três tipos como seguem: i) função lucro - refere-se à receita monetária direta proveniente do cliente; ii) função volume - refere-se ao volume de negócio gerado pelo cliente; e iii) função de salvaguarda - refere-se à possibilidade de garantir um dado nível de negócios e receitas por meio de arranjos contratuais entre a empresa e determinados clientes. Todos estes três tipos de função estão diretamente relacionados com a geração de receita para o provedor.

Já as funções indiretas não têm um efeito imediato, pois dependem de outras atividades para que a criação de valor se concretize. Podem ser divididas em quatro tipos como seguem: i) função inovação - refere-se à possibilidade de inovar em termos de processo e/ou produto por meio de uma função realizada pelo cliente; ii) função marketing - refere-se à possibilidade de conquistar novos clientes por meio de indicação ou promoção realizada pelo cliente; iii) função exploração - refere-se à obtenção de informação referente ao mercado ou ambiente em que o cliente está inserido, por meio deste; e iv) função acesso - refere-se à possibilidade da empresa obter acesso a outros clientes, mercados e profissionais por meio de um cliente (WALTER, RITTER e GEMUNDEN, 2001; MÖLLER e TÖRRÖNEN, 2003).

Contemplando de um modo geral as funções diretas e indiretas, Möller e Törrönen (2003) entendem que estas podem ser agrupadas em três grandes categorias de funções que contribuem na criação de valor, quais sejam, a promoção da eficiência, a promoção da eficácia e o desenvolvimento da rede de 
relacionamentos (networking), conforme apresenta a Figura 3. Considerando tal perspectiva, a Figura 4 relaciona de modo exploratório a principal função que pode ser exercida por cada um dos treze papéis fundamentais identificados na seção 3.1 para a criação de valor em provedores de serviço. Com relação a esta figura, alguns comentários elucidativos são tecidos.

Ao agir como co-produtor o cliente ajuda a reduzir o custo da operação e possibilita um uso mais eficiente dos recursos mobilizados o que pode favorecer diretamente a lucratividade da empresa e/ou viabilizar uma redução no preço do serviço. Neste último caso, provavelmente, ocorreria um efeito positivo sobre o comportamento da demanda. No papel de comprador, o cliente define o provedor de serviço. Caso o mesmo se torne frequente e fiel a uma determinada empresa, tornase mais lucrativo servi-lo. Ao agir como parceiro de outros clientes, o cliente pode afetar positivamente a experiência de serviço deles e isso pode contribuir positivamente para a maior retenção dos mesmos, tornando-se mais lucrativo à empresa servi-los. Ao agir como quase-gerente, o cliente poderá determinar as tarefas que necessita, motivar e induzir os funcionários ao desenvolvimento de novas competências que podem levar a empresa a ofertar um serviço melhor e isso conduz à satisfação da demanda.

Por outro lado, ao agir como concorrente do provedor, o próprio cliente poderá produzir o serviço e provocar uma perda de receita à empresa. De modo semelhante, quando o cliente disputa com outros clientes pelos mesmos recursos oferecidos pela empresa, em alguns casos, pode ocorrer a insatisfação de certos clientes que poderão optar por mudar de provedor de serviço e isso também leva a uma perda de receita. Assim, o desempenho de determinados papéis pode também prejudicar o esforço de criação de valor.

Já ao agir como um agente de inovação, o cliente pode contribuir para a melhoria dos serviços existentes ou para o desenvolvimento de novos serviços, e assim poderá estimular os esforços de inovação da empresa. No papel de instrutor, o cliente pode compartilhar seu conhecimento passando ensinamentos aos funcionários da empresa que o atendem ajudando a assegurar que o serviço certo Ihe seja entregue, e assim pode contribuir para a função Eficácia.

No papel de auditor, o cliente avalia o serviço recebido fornecendo informações sobre a qualidade da empresa e assim atua como explorador do mercado. Motivado por uma boa avaliação da qualidade do serviço, ao divulgar uma imagem positiva da empresa, o cliente pode realizar uma promoção favorável exercendo a função de marketing. Inversamente, uma percepção negativa da qualidade pode motivar o cliente a divulgar uma imagem desfavorável do provedor. Já a função acesso depende da capacidade da empresa em selecionar clientes que possibilitarão o acesso a outros clientes, mercados ou profissionais. São exemplos de clientes com este perfil: i) clientes com grande potencial de vendas, por exemplo, um cliente de uma academia de ginástica que trabalha em uma empresa e ocupa um cargo com certa visibilidade interna poderá atrair seus colegas de trabalho para a mesma academia; ii) clientes que gozam de grande prestígio junto ao público-alvo da empresa podem influenciar positivamente na captação de novos clientes; e iii) clientes que proporcionam um grande aprendizado, seja pelo conhecimento que possuem ou pela necessidade das empresas desenvolverem novas habilidades para melhor atendê-lo. Um exemplo deste tipo de cliente são os portadores de necessidades especiais que requerem recursos, processos e conhecimentos que um provedor de serviço pode não possuir a priori, mas ao se propor a atendê-los, este 
provedor será demandado a desenvolver novas competências que poderão se tornar úteis na abertura de novas frentes de mercado.

Finalmente, a participação do cliente, no papel de insumo, usuário ou produto do processo, não apresenta uma relação direta com as três funções de agregação de valor (eficiência, eficácia e de networking), mas é inerente à operação em si do processo de entrega do serviço. Neste sentido, estes papéis podem ser entendidos como formadores de uma função básica que assegura a realização do serviço e apóia os demais papéis, influenciando-os de modo indireto.

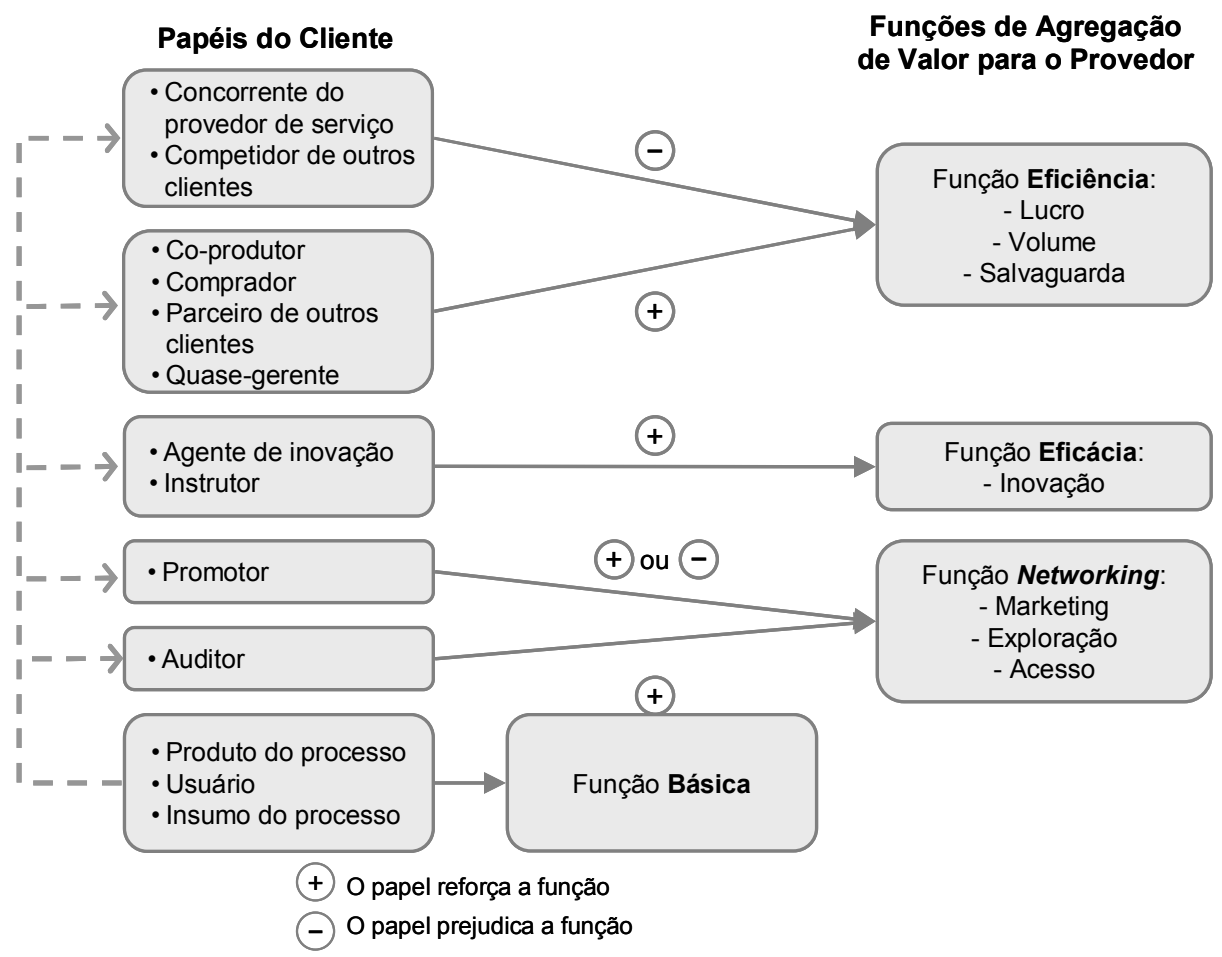

Figura 4 - Potencial contribuição de cada diferente papel para a criação de valor no processo de serviço.

\section{PESQUISA DE CAMPO}

\subsection{Os Serviços Analisados}

A variedade de papéis exercidos pelo cliente depende da natureza do processo de serviço sendo que em muitos serviços a atuação do cliente é bastante limitada. Para investigar como estes diferentes papéis são exercidos pelos clientes, o desenvolvimento do presente trabalho apoiou-se na realização de um estudo de casos múltiplos. Para isso, como unidades de análise foram selecionadas empresas de dois tipos de serviço, quais sejam: i) academias de ginástica, e ii) cursos preparatórios para concursos. Esses serviços apresentam algumas características em comum as quais são descritas a seguir:

- São serviços que processam pessoas, nos quais o cliente cumpre também o papel de insumo e produto do serviço. Nas academias o cliente almeja uma 
mudança em si mesmo, por exemplo, o seu emagrecimento. Nos cursos preparatórios o cliente almeja o domínio do conhecimento sobre o conteúdo que será cobrado no exame do concurso que pretende prestar;

- Ao contrário do que ocorre em muitos tipos de serviços, esses serviços não se finalizam com um único encontro de serviço, pois dependem de uma sequência de vários encontros para que os resultados almejados pelos clientes sejam alcançados. Devido à interdependência entre os diferentes encontros e à necessidade de sua continuidade, para o alcance dos resultados almejados, o provedor do serviço deve estabelecer um relacionamento com o cliente;

- Os resultados almejados pelos clientes que buscam esses serviços dependem da frequência e da maneira como o cliente participa do processo de entrega do serviço. Por exemplo: o emagrecimento almejado pelo cliente ao frequentar uma academia de ginástica, depende, em grande parte, do rigor no cumprimento das atividades físicas prescritas em sua ficha diária de treinamento. O resultado será obtido pelo efeito cumulativo dessas atividades ao longo do tempo.

As características expostas acima indicam que diversos papéis discutidos no referencial teórico podem ser exercidos no serviço das empresas consideradas. A amostra investigada é constituída de quatro casos, sendo dois de cada tipo de serviço considerado. O Quadro 2 descreve as principais características das empresas tomadas como unidades de análise.

Quadro 2 - Empresas pesquisadas e suas características.

\begin{tabular}{|l|l|}
\hline \multicolumn{1}{|c|}{ Empresa } & \multicolumn{1}{c|}{ Características } \\
\hline $\begin{array}{l}\text { Caso 1 - Academia de } \\
\text { ginástica: atividades de } \\
\text { musculação }\end{array}$ & $\begin{array}{l}\text { A organização pesquisada oferece serviços de atividades físicas/fitness: } \\
\text { musculação, ginástica localizada, step, jump, pump, axé, capoeira e } \\
\text { fisioterapia e atende a cerca de 300 alunos. }\end{array}$ \\
\hline $\begin{array}{l}\text { Caso 2 - Grande } \\
\text { academia de ginástica: } \\
\text { atividades de } \\
\text { musculação }\end{array}$ & $\begin{array}{l}\text { A organização faz parte dos serviços oferecidos por um grande clube. Trata- } \\
\text { se de uma academia de grande porte que existe neste clube há cerca de 30 } \\
\text { anos e atualmente possui duas unidades que atendem a cerca de 1.200 } \\
\text { alunos cada uma. O serviço oferecido consiste basicamente da atividade de } \\
\text { musculação. }\end{array}$ \\
\hline $\begin{array}{l}\text { Caso 3 - Curso } \\
\text { preparatório para } \\
\text { concurso de vestibular }\end{array}$ & $\begin{array}{l}\text { Trata-se de uma unidade franqueada de uma grande rede de ensino. Atende } \\
\text { entre 800 e 900 alunos, no total funcionando em três turnos. Além das aulas } \\
\text { propriamente ditas, presta outros serviços de suporte ou reforço, como: } \\
\text { aulas extras, plantões, núcleo de psicologia, monitorias, curso de } \\
\text { aperfeiçoamento em disciplinas específicas, curso básico em matemática } \\
\text { e/ou português. }\end{array}$ \\
\hline $\begin{array}{l}\text { Caso 4 - Curso } \\
\text { preparatório para } \\
\text { concursos públicos na } \\
\text { área de direito }\end{array}$ & $\begin{array}{l}\text { A organização oferece cursos preparatórios para concursos públicos, como } \\
\text { defensor público, etc. Adicionalmente, esta organização disponibiliza cursos } \\
\text { de reciclagem jurídica e de especialização. Existe desde 1991, sendo uma } \\
\text { organização pioneira nessa área. Seu grande público é constituído por } \\
\text { alunos de direito (aqueles que se situam na fase final do curso), advogados } \\
\text { e funcionários públicos. }\end{array}$ \\
\hline
\end{tabular}




\subsection{Os Resultados Encontrados em Campo}

Nos processos de serviço dos casos estudados, foram identificadas oportunidades para o exercício da maioria dos papéis identificados na literatura consultada. O modo de ocorrência (i.e. circunstâncias em que ocorre, frequência) de cada papel foi avaliado qualitativamente com base em dados coletados nas entrevistas, observações diretas realizadas em campo e em pesquisa documental procurando relacionar as diferentes evidências verificadas (SILVERMAN, 2009).

A necessidade ou possibilidade de atuação do cliente em onze dos treze papéis fundamentais considerados pôde ser verificada tanto nas academias de ginástica como nos cursos preparatórios. O Quadro 3 apresenta um resumo dos principais papéis encontrados na literatura e o modo como ocorrem nos casos pesquisados. Apenas os papéis do cliente como instrutor e concorrente do provedor não puderam ser examinados. Todos os demais podem ser desempenhados pelos clientes nos processos considerados, mas diferem em termos da frequência. Dada a natureza dos serviços pesquisados (serviços que têm como objeto principal o próprio cliente), os papéis do cliente como insumo, co-produtor, usuário e produto do processo são fundamentais e assumidos pelos clientes na execução do processo em si. O papel de comprador é primário, mas é concentrado na época de aquisição do serviço. Os papéis como agente de inovação, auditor e promotor, não são intrínsecos ao serviço em si buscado pelo cliente, mas a gerência dos serviços pesquisados, reconhecendo a importância dos mesmos para a eficácia e networking, tem explorado a participação do cliente nestas funções em ocasiões oportunas. Já os papéis do cliente como quase-gerente e competidor ou parceiro de outros clientes, ocorrem apenas eventualmente e a própria gerência tem menor controle sobre os mesmos. No caso particular do cliente como competidor de outros clientes, a gerência procura justamente assegurar condições para evitar a sua ocorrência. 


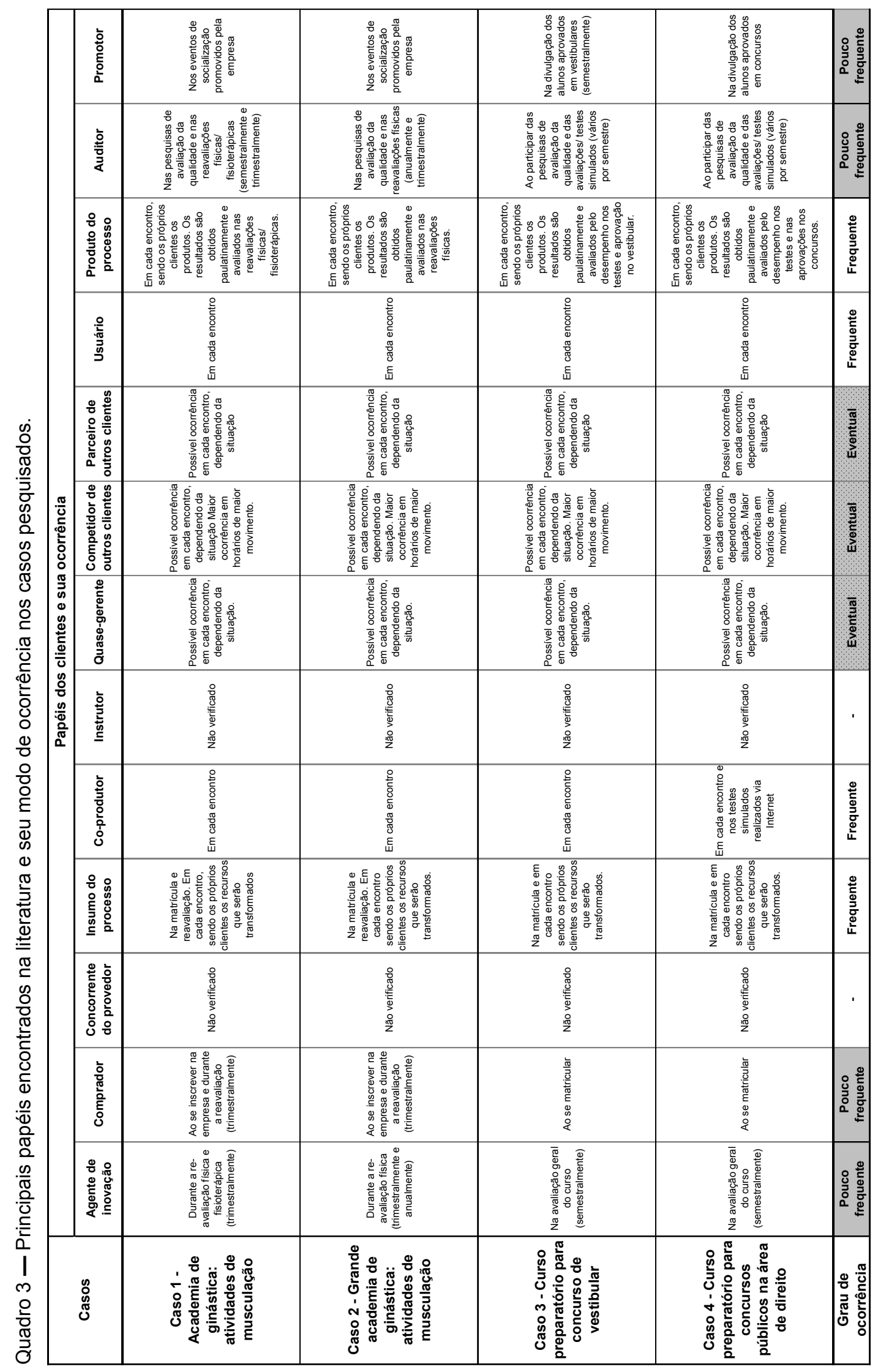


Em relação à maneira como os papéis observados são desempenhados pelos clientes, vale destacar os seguintes aspectos:

a) Cliente como agente de inovação: Nas academias de ginástica o cliente pode executar este papel ao dar sugestões sobre o serviço em si e quando sugere alterações na sua ficha de treinamento, durante a re-avaliação física e fisioterápica. Nos cursos preparatórios o cliente pode executar este papel ao dar sugestões sobre o serviço nas avaliações referentes à qualidade realizadas periodicamente pelas duas empresas pesquisadas. Mas vale ressaltar que a participação do cliente neste papel é limitada à consideração do modo como o serviço será entregue. Normalmente, os clientes não são consultados a respeito de alterações no conteúdo do serviço.

b) Cliente como comprador do serviço: Este papel foi observado em todos os casos pesquisados, pois se referem a tipos de serviço em que o próprio cliente seleciona os serviços que atendem suas necessidades (Ex: escolha do tipo de ginástica que irá exercitar; escolha do assunto e abrangência do curso, escolha da carga horária, escolha do período de ministração, etc.).

c) Cliente como co-produtor: Nas academias de ginástica e nos cursos preparatórios o cliente executa este papel em vários momentos, durante a entrega do serviço. São exemplos: passagem do cartão de identificação na entrada ou saída das academias para registrar dados essenciais ao controle da sua frequência, ajuste do equipamento de musculação para realizar atividades no mesmo; preenchimento dos formulários para matrícula; realização de provas simuladas pela Internet nos cursos preparatórios, etc.

d) Cliente como competidor de outros clientes: Este papel pode ocorrer nos horários de maior movimento, quando o cliente normalmente necessita disputar com outros clientes o uso de alguns recursos do serviço. São exemplos decorrentes de tal situação: a espera pela disponibilidade de aparelhos de musculação para se exercitar em academias de ginástica; a espera pela liberação de uma sala de estudo ou por um livro que está emprestado, etc.

e) Cliente como parceiro de outros clientes: Ocorre quando durante a entrega do serviço, o cliente recebe ajuda ou incentivo de outros clientes e também pode retribuir. São exemplos de tal situação: nas aulas de ginástica em grupo, cada cliente auxilia o outro na execução de exercícios de alongamento; durante atividades de musculação, um cliente pode ajudar o outro no ajuste dos aparelhos; nos cursos preparatórios, um cliente pode esclarecer dúvidas sobre determinado assunto nas sessões de estudo em grupo, etc.

f) Cliente como insumo do processo: Nos serviços analisados o cliente executa este papel ao fornecer inputs ao processo. Em academias de ginástica, 0 cliente fornece dados durante a avaliação física e fisioterápica; nos cursinhos o cliente deve fornecer seus dados para efetivação de sua matrícula. Além disso, pelas características dos serviços analisados, os próprios clientes são também os recursos que serão transformados.

g) Cliente como auditor: O cliente cumpre este papel nas academias de ginástica ao responder as pesquisas de avaliação da qualidade do serviço e nas reavaliações físicas/fisioterápicas em que verifica os resultados obtidos com o serviço. Nos cursos preparatórios, o cliente participa como auditor quando responde as pesquisas de avaliação da qualidade do serviço, e 
quando se submete a avaliações/testes simulados, e verifica o ganho de conhecimento obtido. O resultado obtido nos concursos pelo aluno serve também como uma medida de avaliação do serviço.

h) Cliente como quase-gerente: Nos cursos preparatórios o cliente cumpre este papel ao questionar o professor durante as aulas induzindo o mesmo a buscar novos conhecimentos caso não consiga esclarecer alguma dúvida levantada. Algo semelhante ocorre nas academias, onde o cliente pode demandar do instrutor explicações sobre os exercícios que lhe forem prescritos.

i) Cliente como usuário: Tanto na realização de exercícios de ginástica como em aulas de cursos preparatórios, o próprio cliente participa do processo de serviço desempenhando este papel.

j) Cliente como promotor do serviço: Nos cursos preparatórios, verificou-se que as empresas divulgam os nomes dos alunos aprovados nos concursos e em algumas delas o testemunho de alguns deles é também veiculado. Em academias de ginástica, o cliente participa de caminhadas, festas e pequenos eventos, que são oportunidades para dar visibilidade ao nome da academia em locais públicos.

k) Cliente como produto do processo: Nas academias de ginástica o ganho obtido pelo cliente com relação aos seus objetivos propostos (exemplos típicos: hipertrofia geral intensa, reabilitação muscular, definição muscular, relaxamento, alívio de dores, flexibilidade, emagrecimento, condicionamento físico e correção postural) indica que o próprio cliente é o insumo a ser transformado e produto do serviço. Nos cursos preparatórios, um bom rendimento nas avaliações de aprendizado e a aprovação nos concursos indicam o ganho de conhecimento obtido pelo aluno que inicia como recurso a ser transformado e no decorrer do serviço torna-se produto.

Nos casos investigados, não foi verificada a participação do cliente nos seguintes papéis:

I) Cliente como instrutor: A literatura consultada indica que este papel se faz mais presente em empresas provedoras de serviços mais intensivos em conhecimento em que há necessidade de muita troca de informações entre o cliente e a empresa para a realização dos serviços como ocorre, por exemplo, em atividades de consultoria organizacional.

m) Cliente como concorrente do provedor: Trata-se de um papel que pode ser exercido pelos clientes dos tipos de serviço contemplados, mas não pode ser verificado nesta pesquisa. As academias de ginástica podem ter de concorrer com os aparelhos domésticos de musculação que possibilitam a realização do serviço na própria residência dos clientes. Já os alunos dos cursos preparatórios têm a alternativa de se prepararem para os concursos de maneira individual. O papel do cliente como concorrente do provedor não pode ser examinado na medida em que para sua verificação seria necessário obter dados com usuários, ex-usuários e não usuários dos serviços pesquisados e, no presente trabalho, a coleta de dados foi efetuada principalmente por meio de entrevistas semi-estruturadas com os gestores de operações dos serviços analisados. 
Enxergando o cliente como um elemento que pode participar do processo de serviço contribuindo na melhoria da qualidade e produtividade do sistema, a gerência de empresas de serviço pode implementar mecanismos que promovam uma inserção mais participativa dos clientes. Quando os clientes têm uma maior participação no processo de serviço, torna-se relativamente mais fácil para a organização construir um relacionamento com os mesmos, pois isso pode aumentar a confiança dos clientes nos funcionários e a percepção de que a organização oferece uma atenção mais individual. Como salientam Claycomb et al. (2001), o estabelecimento de um melhor relacionamento com os clientes favorece a retenção dos mesmos e é menos custosa que a conquista de novos clientes para a empresa.

Nos estudos de casos realizados, procurou-se também analisar como a gerência das empresas pesquisadas tem buscado esta forma de participação.

Quadro 4 - Principais táticas utilizadas para promover maior participação dos clientes.

\begin{tabular}{|c|c|c|}
\hline $\begin{array}{l}\text { Papéis do } \\
\text { cliente }\end{array}$ & Táticas observadas & Exemplos \\
\hline $\begin{array}{l}\text { Agente de } \\
\text { inovação }\end{array}$ & $\begin{array}{l}\text { Implementação de } \\
\text { programas que capturem } \\
\text { propostas de inovação dos } \\
\text { clientes. }\end{array}$ & $\begin{array}{l}\text { Nas academias de ginástica a ficha de treinamento que } \\
\text { prescreve os exercícios a serem feitos pelo cliente é } \\
\text { elaborada com sua participação, incluindo suas } \\
\text { sugestões e preferências. } \\
\text { Em um curso preparatório, os alunos são convidados a } \\
\text { sugerir modificações no curso na avaliação final do } \\
\text { semestre. }\end{array}$ \\
\hline Comprador & $\begin{array}{l}\text { Oferecimento de planos com } \\
\text { descontos conforme o } \\
\text { tempo ou frequência de } \\
\text { uso. }\end{array}$ & $\begin{array}{l}\text { Descontos pelo tipo de plano escolhido (trimestral, } \\
\text { semestral ou anual), incentivando uma maior } \\
\text { permanência no serviço. }\end{array}$ \\
\hline $\begin{array}{l}\text { Concorrente } \\
\text { do provedor }\end{array}$ & Não encontrada. & Não encontrado. \\
\hline $\begin{array}{l}\text { Insumo do } \\
\text { processo }\end{array}$ & $\begin{array}{l}\text { Realização de diagnóstico } \\
\text { do cliente para identificar o } \\
\text { processo de serviço mais } \\
\text { adequado a ser iniciado. }\end{array}$ & $\begin{array}{l}\text { As academias de ginástica realizam diagnóstico inicial } \\
\text { (avaliações física e fisioterápica) de todos os clientes } \\
\text { para coletar informações individualizadas. }\end{array}$ \\
\hline Co-produtor & $\begin{array}{l}\text { Orientação e treinamento do } \\
\text { cliente durante a execução } \\
\text { das suas tarefas, } \\
\text { habilitando-o a executá-las } \\
\text { corretamente. }\end{array}$ & $\begin{array}{l}\text { Nas academias de ginástica, as atividades realizadas } \\
\text { pelos clientes são acompanhadas por monitores que } \\
\text { procuram assegurar que estes executem } \\
\text { corretamente as atividades de co-produção como, por } \\
\text { exemplo, o ajuste de aparelhos. }\end{array}$ \\
\hline Instrutor & Não encontrada. & Não encontrado. \\
\hline $\begin{array}{l}\text { Quase- } \\
\text { gerente }\end{array}$ & $\begin{array}{c}\text { Inexistente na literatura } \\
\text { consultada. }\end{array}$ & Não encontrado. \\
\hline $\begin{array}{l}\text { Competidor } \\
\text { de outros } \\
\text { clientes }\end{array}$ & $\begin{array}{l}\text { Definição de regras de } \\
\text { conduta que devem ser } \\
\text { respeitadas pelos clientes } \\
\text { quando utilizam os } \\
\text { serviços. } \\
\text { Implementação de } \\
\text { programas de educação e } \\
\text { orientação. } \\
\text { Punição do mau }\end{array}$ & $\begin{array}{l}\text { As academias de ginástica definiram regras quanto ao } \\
\text { uso de roupas adequadas e uso dos aparelhos. } \\
\text { Em uma academia pesquisada, as regras de } \\
\text { comportamento são divulgadas por meio de banners } \\
\text { e eventuais excessos de comportamentos dos } \\
\text { clientes são tratados por uma comissão de disciplina. } \\
\text { Nos cursos preparatórios há regras quanto ao } \\
\text { comportamento dos alunos em sala de aula e uso dos } \\
\text { recursos oferecidos. Os assuntos relacionados às }\end{array}$ \\
\hline
\end{tabular}




\begin{tabular}{|c|c|c|}
\hline & comportamento. & normas disciplinares são afixados em mural. \\
\hline $\begin{array}{l}\text { Parceiro de } \\
\text { outros } \\
\text { clientes }\end{array}$ & $\begin{array}{l}\text { Realização de atividades } \\
\text { que promovem uma maior } \\
\text { socialização entre os } \\
\text { clientes. }\end{array}$ & $\begin{array}{l}\text { Em três das quatro empresas pesquisadas são } \\
\text { promovidas festas de confraternização. }\end{array}$ \\
\hline Usuário & $\begin{array}{l}\text { Estabelecimento de uma } \\
\text { comunicação eficiente } \\
\text { com o cliente, } \\
\text { disponibilizando } \\
\text { informações relevantes } \\
\text { sobre o serviço. } \\
\text { Fornecimento de suporte ao } \\
\text { cliente durante a } \\
\text { realização das atividades, } \\
\text { orientando, esclarecendo } \\
\text { dúvidas e estimulando sua } \\
\text { participação }\end{array}$ & $\begin{array}{l}\text { Todas as empresas utilizam cartazes que divulgam } \\
\text { informações sobre a programação, preços, instruções } \\
\text { para o uso dos serviços, lembretes, avisos, } \\
\text { notificação de mudanças, etc. } \\
\text { Nas academias de ginástica, monitores acompanham a } \\
\text { realização dos exercícios físicos feitos pelos alunos } \\
\text { fornecendo suporte e incentivando a realização dos } \\
\text { mesmos. } \\
\text { Os cursos preparatórios monitoram a frequência do } \\
\text { cliente, induzindo sua assiduidade. Também } \\
\text { fornecem suporte aos alunos por meio de monitores e } \\
\text { amplo acesso a vários tipos de informações no site da } \\
\text { empresa. }\end{array}$ \\
\hline Auditor & $\begin{array}{l}\text { Disponibilização de } \\
\text { instrumentos adequados } \\
\text { para o cliente realizar a } \\
\text { avaliação do serviço. }\end{array}$ & $\begin{array}{l}\text { Todas as empresas disponibilizam canais adequados } \\
\text { que possibilitam aos clientes informar sua avaliação } \\
\text { do serviço. }\end{array}$ \\
\hline Promotor & $\begin{array}{l}\text { Premiar ou recompensar a } \\
\text { participação do cliente } \\
\text { como promotor. }\end{array}$ & $\begin{array}{l}\text { Nos cursos preparatórios os nomes dos ex- } \\
\text { alunos/alunos aprovados são divulgados } \\
\text { publicamente. } \\
\text { Em um curso preparatório, alguns ex-alunos aprovados } \\
\text { em concursos são convidados a publicar um pequeno } \\
\text { testemunho ou mensagem de incentivo nos meios de } \\
\text { divulgação da empresa. }\end{array}$ \\
\hline
\end{tabular}

O Quadro 2 sintetiza as principais táticas utilizadas pelas empresas pesquisadas para a promoção de uma maior participação dos clientes. Observa-se que as empresas analisadas promovem predominantemente papéis que fortalecem as funções Básica, de Eficiência e de Networking. Já a função Eficácia é estimulada de modo incipiente, pois em ambos tipos de serviços considerados, as sugestões dos clientes estão limitadas ao modo de entrega do serviço. Não foi constatada uma participação mais ampla do cliente no planejamento do serviço como um todo.

Vale destacar que no presente estudo, a pesquisa de campo foi direcionada à observação e análise de serviços que por envolver maior participação do cliente no processo, possibilitam que este venha a assumir uma maior variedade de papéis. Contudo, em serviços em que o processo é mais restrito, envolvendo uma única ou poucas interações de duração mais curta entre o cliente e o provedor, bem como entre o cliente e outros clientes, a variedade de papéis que podem ser assumidas tende a ser menor (ex. atendimento via Unidade de Resposta Audível (URA), serviço de conveniência buscado fora da rotina, serviço padronizado com proposta de baixo custo e rapidez). 


\section{CONSIDERAÇÕES FINAIS}

A pesquisa de campo evidenciou o exercício de onze papéis que o cliente pode realizar nos serviços e que afetam a qualidade e produtividade nos processos das empresas provedoras de serviços. $O$ estudo também identificou na literatura várias estratégias que podem ser utilizadas pelos gestores das empresas para incentivar a maior participação dos clientes no serviço, sendo que a prática de muitas delas pôde ser constatada na pesquisa de campo.

De modo exploratório, o trabalho propôs relacionar os papéis que o cliente pode desempenhar nos serviços com as funções de agregação de valor para o provedor. O quadro conceitual apresentado pode orientar os gestores de serviços na análise de seu processo de relacionamento de modo a identificar lacunas que revelem novas oportunidades de agregação de valor por meio das funções promotoras da eficiência, eficácia e networking.

Vale ressaltar que com o acesso à grande quantidade de informações disponibilizada atualmente pelas diferentes ferramentas de tecnologia da informação, os clientes têm a possibilidade de ter ao seu alcance praticamente o mesmo nível de informação que as empresas. Neste novo contexto, os clientes podem ser vistos como uma fonte de competências por deterem um certo know-how sobre o serviço, além de novos conhecimentos específicos que podem ser agregados ao serviço. Nesta direção, os clientes tendem a se tornar agentes importantes para a divulgação da imagem das empresas a outros potenciais clientes, e podem influenciar no desenvolvimento de novos serviços demandando soluções para necessidades ainda não atendidas que irão requerer um avanço no conhecimento detido pelas empresas. Como bem destacam Gibbert, Leibold e Probst (2002), mais do que conhecer bem o cliente, atualmente, as empresas necessitam capturar o conhecimento dos clientes e explorar este recurso para cativá-los e fidelizá-los. Neste novo contexto, torna-se importante colocar as necessidades dos clientes e suas expectativas em primeiro plano, o que significa uma mudança de perspectiva para a empresa: o olhar gerencial deve deixar de ser de dentro para fora e passar a ser de fora para dentro. Isto demanda a estruturação de um sistema que efetivamente conduza ao envolvimento dos clientes nos papéis discutidos neste trabalho. Nesta direção, dois grandes esforços se fazem necessários:

i) Melhoria substancial da comunicação entre a empresa e os clientes o que demanda o projeto de melhores canais de comunicação entre ambos, sendo que as tecnologias de informação oferecem várias possibilidades para esta finalidade; e

ii) Estruturação de um ambiente de trabalho adequado a esta nova realidade que privilegie e suporte o desenvolvimento de novas competências nos funcionários, voltadas não apenas aos aspectos técnicos do serviço, mas também às habilidades emocionais e comunicativas. Vale observar, que quanto maior o envolvimento do cliente nos serviços, mais contatos ocorrerão entre os funcionários e os mesmos.

Talvez, este segundo ponto represente um desafio maior para as organizações de serviço. Graf (2007) destaca que na área de gestão de recursos humanos, a atenção dos gestores ainda se concentra em funções tradicionais realizadas pelo departamento de recursos humanos e se restringe a fatores 
organizacionais internos. Isso evidencia a necessidade de buscar maior sintonia com a tendência de privilegiar uma maior interação da empresa com o meio externo e, em especial, com os seus clientes. Nesta direção, este autor indica várias ações voltadas à gestão de recursos humanos que se fazem necessárias para estabelecer e dar suporte a um maior envolvimento dos clientes nos serviços. São elas:

- Dar maior importância aos aspectos emocionais e comunicativos presentes no trabalho. Isto implica na construção e na manutenção de relacionamentos baseados na confiança que é um pré-requisito para a troca de informações, conhecimentos, experiências e idéias;

- Ampliar e modificar as tarefas dos funcionários possibilitando o desenvolvimento e o uso de novas competências no seu dia a dia;

- Preparar o funcionário para lidar adequadamente com os conflitos e ambiguidades de papel existentes na sua interação com o cliente, pois quanto mais complexo for o papel do segundo, mais complexo e desafiador será o papel do primeiro. Nesta situação, as possibilidades da ocorrência de conflitos e ambiguidades de papel aumentam. O conflito pode ser entendido como resultante da discrepância entre o que o funcionário pensa que o cliente quer que ele faça e o que o funcionário pensa que o gerente quer que ele faça;

- Tornar as formas de promoção, remuneração, premiação, etc. condizentes com o novo papel que o funcionário deverá realizar.

Vale salientar que a "abordagem da linha de produção", discutida na introdução deste trabalho, não considera várias possibilidades de utilizar o cliente como uma fonte de agregação de valor ao provedor do serviço, portanto, as idéias aqui apresentadas levam a questionar a pertinência de manter esta estratégia em vários serviços que atualmente se apóiam nela.

O estudo mais profundo dos papéis que os clientes podem desempenhar nos serviços pode render a identificação de alternativas que viabilizam uma melhoria da qualidade e produtividade nos processos de serviço, além da elevação do valor dos serviços oferecidos. Este trabalho procurou delinear a natureza destas alternativas e apontar as oportunidades de melhoria ou inovação que estas podem proporcionar a pesquisadores e gestores que estejam buscando novos referenciais teóricos e metodológicos para a concepção, implementação e controle de operações de serviços.

\section{AGRADECIMENTO}

O segundo autor agradece o apoio do CNPq (PQ 307387/2007-0).

\section{REFERÊNCIAS}

AUH, S.; BELL, S.J.; McLEOD, C.S.; SHIH, E. Co-production and customer loyalty in financial services, Journal of Retailing, v. 83, n. 3, p. 359-370, 2007.

BENDAPUDI, N.; LEONE, R. P. Psychological Implications of Customer Participation in Co-Production, Journal of Marketing, v. 67, n. 1, p. 14-28, 2003. 
BITNER, M. J.; FARANDA, W. T.; HUBBERT, A. R.; ZEITHAML, V. A. Customer contributions and roles in service delivery. International Journal of Service Industry Management, v. 8, n. 3, p.193- 205, 1997.

BOWEN, D. E. Managing customers as human resources in service organizations. Human Resource Management, v. 25, n. 3, p. 371-383, 1986.

CHAN, K. W.; YIM, C. K.; LAM, S. S.K. Is Customer Participation in Value Creation a Double-Edged Sword? Evidence from Professional Financial Services Across Cultures, Journal of Marketing, v. 74, p. 48-64, 2010.

CHASE, R. B. Where does the customer fit in a service operation? Harvard Business Review, Nov./Dec., p. 137-142, 1978.

CHERVONNAYA, O. Customer role and skill trajectories in services, International Journal of Service Industry Management, v. 14, n. 3, p. 347-363, 2003.

CLAYCOMB, C.; LENGNICK-HALL, C. A.; INKS, L.W. The customer as a productive resource: a pilot study and strategic implications, Journal of Business Strategies, v. 18, n. 1, p. 47-69, 2001.

ETGAR, M. A descriptive model of the consumer co-production process, Journal of the Academic Marketing Science, v. 36, p. 97-108, 2008.

GIBBERT, M.; LEIBOLD, M., PROBST, G. Five styles of customer knowledge management and how smart companies use them to create value, European Management Journal, v. 20, n. 5, p. 459-469, 2002.

GRAF, A. Changing roles of customers: consequences for HRM, International Journal of Service Industry Management, v. 18, n. 5, p. 491-509, 2007.

GROVE, S. J.; FISK, R. P. The impact of others customers on service experiences: a critical incident examination of "getting along". Journal of Retailing, v. 73, n. 1, p. 6385, 1997.

HAKSEVER, C.; RUSSELL, R. S.; RENDER, B. Service management and operations. New Jersey: Prentice Hall, 2000, 584 p.

HOFFMAN, K. D.; BATESON, J. E. G. Princípios de marketing de serviços: conceitos, estratégias e casos. São Paulo: Pioneira Thomson Learning, 2003.

JOHNSTON, R.; CLARK, G. Service Operations Management: improving service delivery, London: FT Prentice Hall, $3^{\text {rd }}$ Edition, 2008.

LENGNICK-HALL, C. A. Customer contributions to quality: a different view of the customer-oriented firm. The Academy of Management Review, v. 21, n. 3, p. 791824, 1996.

LEVITT, T. Production-line approach to service. Harvard Business Review, Sep.- 
Oct., p. 41-52, 1972.

LOVELOCK, C. H.; WRIGHT, L. Serviços: marketing e gestão. São Paulo: Saraiva, 2002, $416 \mathrm{p}$.

LOVELOCK, C. H.; YOUNG, R. F. Look to consumers to increase productivity. Harvard Business Review, May/June, p. 168-178, 1979.

LUSCH, R. F.; VARGO, S. L.; WESSELS, G. Toward a conceptual foundation for service science: contributions from service-dominant logic IBM Systems Journal, v. 47, n. 1, 2008.

MCCUTCHEON, D.M.; MEREDITH, J.R. Conducting case study research in operations management, Journal of Operations Management, v. 11, p. 239-256, 1993.

WINNERMILLS, P. K.; MORRIS, J. H. Clients as partial employees of service organizations: role development in client participation. The Academy of Management Review, v. 11, n. 4, p. 726-735, 1986.

MÖLLER, K.E.K.; TÖRRÖNEN, P. Business suppliers' value creation potential A capability-based analysis Industrial Marketing Management, v. 32, n.2, p. 109-118, 2003.

OUSCHAN, R.; SWEENEY, J.; JOHNSON, L. Customer empowerment and relationship outcomes in healthcare consultations, European Journal of Marketing, v. 40, n. 9/10, p. 1068-1086, 2006.

PAYNE, A. F.; STORBACKA, K.; FROW, P. Managing the co-creation of value, Journal of the Academic Marketing Science, v. 36, p. 83-96, 2008.

PRAHALAD, C.K.; RAMASWAMY, V. Co-opting customer competence, Harvard Business Review, January/February, p. 79-87, 2000.

RAVALD, A.; GRÖNROOS, C.; The value concept and relationship marketing, European Journal of Marketing, v. 30, n. 2, p. 19-30, 1996.

SILVERMAN, D. Interpretação de Dados Qualitativos: métodos para análise de entrevistas, textos e interações, Porto Alegre: Artmed, 2009, $3^{\mathrm{a}}$ ed.

SLACK, N.; JOHNSTON, R.; CHAMBERS, S. Administração da produção, São Paulo: Atlas, 2001.

TORRES JÚNIOR, N. Operações em serviços de resultados ulteriores: diretrizes gerenciais para um melhor desempenho. 2007. 224 p. Tese (Doutorado). Departamento de Engenharia de Produção, Escola Politécnica, Universidade de São de Paulo. São Paulo, 2007.

TORRES JÚNIOR, N.; MIYAKE, D. I. Os papéis do cliente nos serviços: uma discussão acerca das possibilidades de sua participação na criação de valor e 
melhoria da qualidade In: XXVIII Encontro Nacional de Engenharia de Produção ENEGEP, Rio de Janeiro, 2008. Anais. Rio de Janeiro, 13 a 16 de outubro de 2008, CD ROM.

ULWICK, A.W. Turn customer input into innovation, Harvard Business Review, January, p. 91-97, 2002.

VON HIPPEL, E. Innovation by user communities: learning from open-source software, MIT Sloan Management Review, Summer, p. 82-86, 2001.

WALTER, A.; RITTER T.; GEMÜNDEN, H. G. Value creation in buyer-seller relationships: theoretical considerations and empirical results from a supplier's perspective, Industrial Marketing Management, v. 30, p. 365-377, 2001.

WEMMERLOV, U. A taxonomy for service process and its implications for system design. International Journal of Service Industry Management, v. 1, n. 3, p. 20-40, 1990.

WIKSTRÖM, S. The customer as co-producer. European Journal of Marketing, v. 30, n. 4, p. 6-19, 1996.

YIN, R. K. Estudo de caso: planejamento e métodos. Porto Alegre: Bookman, 2001, $199 \mathrm{p}$.

ZEITHAML, V. A; BITNER, M. J. Marketing de serviços: a empresa com foco no cliente. Porto Alegre: Bookman, 2003, 536 p.

\section{Anexo A - Roteiro de Entrevista}

Dados gerais da empresa/instituição

1) Nome:

2) Número de funcionários:

3) Principais recursos existentes:

4) Tempo de existência:

5) Público alvo:

6) Principais stakeholders:

7) Serviços oferecidos:

8) Capacidade de atendimento:

9) Prêmios ou certificações obtidos:

Descrição do processo de serviço

1) Descreva as principais sequências existentes para a entrega do serviço.

2) Quais sequências de atividades são registradas (monitoradas)?

Rotina de diagnóstico do cliente

1) Existe uma rotina de diagnóstico do cliente para definir as atividades que serão

realizadas, quando o mesmo ingressa no serviço? Caso afirmativo, como isto é feito?

(Cliente como insumo do processo e comprador do serviço)*

Rotina de seleção dos clientes

1) Existe uma rotina de seleção dos clientes para ingressar no serviço? Caso afirmativo, como isto é feito? (Cliente como insumo do processo)*

Modos de inserção ou envolvimento do cliente no serviço

1) A empresa educa e treina o cliente para a realização das atividades? Caso afirmativo, como isto é feito? 


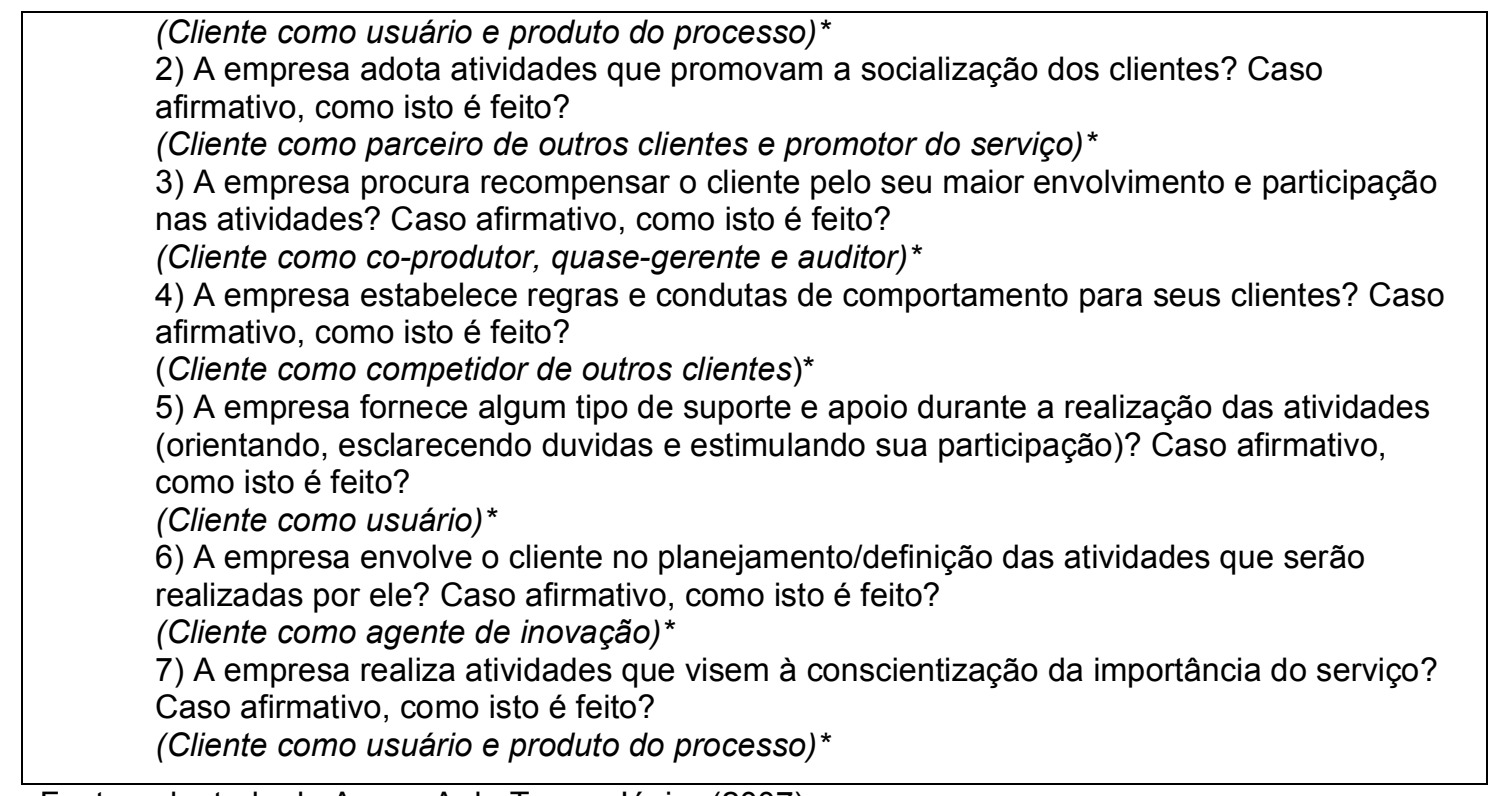

Fonte: adaptado do Anexo A de Torres Júnior (2007).

* Texto acrescentado ao roteiro original para facilitar a identificação pelo leitor dos papéis analisados na pesquisa. 